\title{
A CONSTITUIÇÃO DO IMAGINÁRIO DE LÍNGUA NA ESCRITA DE ACADÊMICOS DE LETRAS
}

\author{
Gesualda de Lourdes dos Santos Rasia
}

\begin{abstract}
$\boldsymbol{R} \boldsymbol{E} \boldsymbol{S U M E}:$ Réfléchir sur l'enseignement de la langue portugaise dans l'horizon des questions théoriques formulées et discutées par l'Analyse du Discours (AD) française implique (re)mettre en cause la dimension politique de l'enseignement de langue. Dans cette perspective, on propose une réflexion sur les moyens avec lesquels les sujets en procès de formation initiale en Lettres, à l'Université, pensent à propos du savoir linguistique. Dans quelle mesure les discours de ces élèves reproduisent des savoirs de l'ordre du sens commun ou produisent des ruptures à partir du contat avec l'ordre de la science? Pour répondre à cette problématique, on analyse des énoncés présents dans des textes d'élèves universitaires qui ont écrit sur ses expériences aux classes de portugais à l'école élémentaire et sur la connaissance qu'ils possédent à propos du langage. L'analyse du Discours constitue, dans cette sphère, une discipline qui peut promouvoir des déplacements dans la relation du sujet avec le savoir sur le langage, notamment à travers des réflexions promues à partir de la notion de hiperlangue.
\end{abstract}

PALAVRAS-CHAVE: língua, imaginário, ensino, saberes, ordem do senso comum, ordem da ciência.

Pensar o ensino de língua portuguesa, hoje, no horizonte das questões teóricas formuladas pela Análise do Discurso francesa (AD), implica recolocar na mesa dos debates a dimensão política desse ensino. Interessada nos processos histórico-sociais em jogo na constituição da linguagem, a AD reposicionou a relação linguagem-sociedade, na medida em que postulou a constituição dialética de ambas, e isso de modo não homogêneo. O linguístico passou a ser tomado a partir da exterioridade que lhe é constitutiva, e por isso a relevância que passou a assumir o funcionamento da língua enquanto instância de produção de sentidos. Vale lembrar que a $\mathrm{AD}$ não se constituiu como proposta de caráter de aplicação imediata, no entanto, justamente por deslocar substancialmente o modo de conceber a linguagem e a relação com o conhecimento, possibilitou que pudessem ocorrer rupturas nas relações com o saber sobre a língua. Tal deslocamento, contudo, não impediu que, no âmbito das práticas de ensino, se mantivessem posturas conservadoras, as quais concebem a língua como estrutura ausente de seus usuários e de condições de produção específicas. Isso se dá, em parte, porque embora a dimensão do ensino conte com o fundamento de teorias contemporâneas, e toda teoria seja, em essência, política, nos termos de Guimarães e Orlandi (2006), nem todas colocam "o político como elemento próprio das relações sociais". Considerar a dimensão política constitutiva do ensino de língua corresponde, por exemplo, a tomar a relação norma/uso como constitutiva dos conflitos e das diferenças sociais. 
Nessa perspectiva, o presente estudo aborda o imaginário de língua constituído por sujeitos em fase inicial de formação no curso de Letras-Português, da Universidade Federal do Paraná (UFPR) especialmente a partir dos aspectos que dizem respeito à relação norma versus uso ${ }^{1}$. A posição-sujeito acadêmico inscreve-se, nesse processo, nos saberes formulados no intervalo entre a ordem do senso comum e a ordem da cientificidade, lugar a partir do qual são tecidos embates de identificação e de desidentificação, resultado decorrência de interpelações decorrentes das duas ordens em jogo. As produções linguageiras são tomadas, assim, como instâncias de constituição dos sujeitos e dos sentidos, numa relação que é inseparável e que implica o atravessamento da ordem do ideológico.

Minha prática pedagógica em componentes curriculares que abordam a leitura e a produção de textos tem partido essencialmente de questões relacionadas à língua, constituindo, a prática escrita a partir de reflexões de ordem metalinguística e político-social. Nesse processo tenho percebido que os acadêmicos, quando chamados a se deslocarem da condição de simples usuários da língua para a de sujeitos que refletem sobre esta, fazem emergir em suas formulações espaços de discurso que materializam confrontos de ordem política no que dizem sobre a língua e no modo como materializam esse dizer. Trata-se de formulações que reportam à própria constituição contraditória da instância normativa, a qual "emerge exatamente do uso linguístico" (MOURA NEVES, 2004). Esse trajeto de legitimação se dá em uma perspectiva histórica, a qual, para além das implicações da linha do tempo, conta com as de ordem política, no sentido de que a cristalização de alguns usos promove a varredura de outros, passando a circunscrevê-los no domínio de um fora interditado.

A divisória desaparece, no entanto, sob o efeito de naturalização diante do fato de que há $\boldsymbol{a}$ língua portuguesa, normatizada, reconhecida pelos manuais, em contrapartida às realizações situadas na ordem da diferença, debitadas à razão do espaço geográfico, da condição social do falante, dentre outras variáveis. Assim, importa perguntar, no presente estudo, acerca de algumas questões, tais como: de que lugares da rede do interdiscurso emanam os enunciados que dizem sobre essa língua? Que furos compõem essa tessitura, esgarçada pelo tempo e naturalizada pela suposta ausência de conflitos políticos e sociais? Para além do dizer sobre, como se apresenta a língua em si, matéria contraditória, cuja propriedade é a diferença, a não unicidade? E ao se apresentar na condição da variança, da diferença, como se apreendem, aí, os movimentos simultâneos de entrega e de resistência do sujeito usuário? É a isso, dentre outras questões, que este estudo pretende responder.

Os estudantes, ao adentrarem as discursividades próprias do espaço acadêmico, passam por um processo de reconfiguração gradual dos saberes que possuem acerca da língua. Nessa passagem se tece a luta entre a reprodução dos saberes do senso comum, do tipo "o brasileiro não sabe a sua língua", e enunciados da ciência linguística, os quais relativizam afirmações dessa ordem. Construir o entendimento do que seja "saber a sua língua" implica, necessariamente, um deslocamento de ordem política, dadas as condições mesmas de constituição do português brasileiro, as condições de escolarização, além da instituição dos instrumentos linguísticos no Brasil, tais como gramáticas e dicionários. Em face dessa complexidade, busco focar, na discursividade em análise, os espaços em que esse entendimento se constitui, procurando pistas, na materialidade linguística, da ordem política que aí se inscreve. É preciso, para tanto, considerar as condições históricas que produzem sentidos acerca do saber linguístico e acerca dos sujeitos que frequentam a academia de Letras hoje. São eles, em sua grande maioria, oriundos de classes menos favorecidas

\footnotetext{
1 Em que pesem os equívocos e sobreposições latentes a essas duas designações, são elas aqui empregadas, respectivamente, como instância do regramento gramatical e instância da resistência à normatização.
} 
economicamente, os quais buscam uma formação que amplie as possibilidades de ingresso imediato no mercado de trabalho. A esses soma-se uma outra parcela, menor, de diplomados de áreas diversas, que buscam na formação em Letras o aprimoramento dos conhecimentos acerca da linguagem, com vistas ao aperfeiçoamento da língua escrita em suas atividades profissionais, com consequente ampliação das possibilidades de inserção e ascensão profissional. Essa descrição, ainda que ampla e generalizante, me conduz a pensar sobre os sentidos que o "saber a língua" produz para sujeitos inscritos em situações de certo modo distintas, embora ambas orientadas por um valor de caráter mercadológico. Diante disso, algumas questões despontam, dentre elas, como esse "saber a língua" emerge em seus discursos e que determinações o atravessam.

Retornando à questão da variação, vale dizer que a gramática, como um dos lugares que derivam cristalizações acerca do que seja "saber a língua", concede à diferença e à variação lugar ínfimo e marginal (quando o faz), porque emergente nos desvãos das formulações. O olhar sobre esses desvãos e sobre o que se diz acerca deles leva a perguntar acerca do que está em jogo na relação da história com a materialidade linguística, sobre como esses saberes são (re)formulados pelos acadêmicos de Letras.

No âmbito da academia, tais discussões têm estabelecido um espaço teórico privilegiado para abordagem, normalmente aquele que foca os estudos de ordem sociolinguística, os quais põem em relação dicotômica o par norma/uso e estabelecem relações de causa e efeito na tomada das variantes linguísticas pelos usuários. A posição construída sobre essa questão no âmbito dos estudos discursivos é que as questões relacionadas à variação linguística, aos usos da linguagem, ao embate norma/variação podem ser pensadas a partir de pressupostos teóricos que possibilitem o deslocamento da perspectiva do dado para a do fato. Isso significa conceber os registros linguísticos como significando a partir de sua representação de ordem política, via materialidade da linguagem, que é simultaneamente linguística e histórica. (ORLANDI, 1990). Tal deslocamento implica a abordagem da linguagem em sua relação com a exterioridade como constitutiva, o que resulta no fato de que as questões concernentes à tomada da relação norma/variação, por exemplo, passem a significar não apenas pelas variáveis como condição social, locus geográfico, faixa etária, entre outras, mas a partir do entendimento sobre os modos como a relação dessas variáveis com os registros de linguagem faz significar a língua enquanto condição identitária de seus usuários.

Gadet (2005) pontua que a AD propõe o discurso como foco, e, ao fazê-lo, leva em conta um nível intermediário entre o social e um sistema de língua do qual essa instância hipoteticamente teria sido subtraída. Esse deslocamento produz resultado teóricometodológico que leva a perguntas do tipo: "diferentes grupos sociais dizem a mesma coisa dizendo diferentemente?" "as diferentes formulações, determinadas por diferentes posições enunciativas, reportam à produção de sentidos diferentes?" É o estatuto da variação linguística que está em discussão, numa ancoragem em postulados de vertente marxista, no interior da qual se preconiza a existência de um valor simbólico produzido pelos diferentes registros linguísticos para seus usuários. O deslocamento da relação causa/efeito, própria da abordagem variacionista, para a tomada da relação norma/uso a partir de noções teóricas próprias da $\mathrm{AD}$, tais como interdiscurso, memória, equívoco e vacilo, reporta à tomada da língua enquanto produção de discursos, e esses enquanto produção de sujeitos e de sentidos, inelutavelmente inseparáveis.

A análise dos enunciados produzidos pelos acadêmicos acerca dos usos da língua conduz, pois, a refletir acerca do imaginário composto por essa instância de discurso, ou seja, acerca das representações que os sujeitos constroem sobre a língua. E, ainda, como as 
relações sociais encontram-se simbolizadas nessas representações. Tendo em vista o lugar de entremeio em que se inscrevem os estudantes de Letras em fase inicial de curso, divididos entre duas ordens distintas, conforme já discutido, importa apreender aos atravessamentos que compõem tal imaginário, a partir da ordem do senso comum e da ordem da ciência. Nas palavras de Chauí (2004, p.217), “(...) (a ciência) só estabelece relações causais em decorrência de uma investigação que considera as relações com os semelhantes e os diferentes; também porque surpreende-se com a regularidade, a constância, a frequência, a repetição, buscando mostrar que o extraordinário não passa de um caso particular do que é regular. O senso comum, em contrapartida, tem seus pressupostos e formulações circunscritos na ordem da subjetividade, da individualização e da generalização."

O quesito generalização, embora presente nas duas ordens, difere, segundo a mesma autora, porque enquanto a ciência busca encontrar o que une os objetos em sua diversidade, no senso comum, a tendência é estabelecer relações imediatas de causa e efeito entre as coisas ou os fatos, produzindo cristalizações. E desses lugares de suposta estabilidade derivam-se preconceitos que norteiam a interpretação da realidade, no caso, a realidade linguística. $\mathrm{O}$ senso comum marca-se, ainda, pelo fato de que "não se surpreende nem se admira com a regularidade, constância, repetição e diferença das coisas, mas, ao contrário, a admiração e o espanto se dirigem para o que é imaginado como único, extraordinário, maravilhoso ou miraculoso." (op.cit.)

Entendo que os conflitos/confrontos entre essas duas ordens correspondem, em certa medida, ao embate entre a noção de língua imaginária, "aquela que os analistas fixam com suas sistematizações" e a língua fluida, "que não se deixa imobilizar nas redes dos sistemas e das fórmulas" (ORLANDI, op. cit.). Os sujeitos acadêmicos, ao inscreverem-se numa posição que exige um olhar-outro sobre a língua, o olhar do distanciamento, produzem sentidos a partir da irrupção do equívoco, porque dizem a língua ora do lugar do regramento, ora do lugar que permite e aceita a variação, o diferente, a transgressão.

Os fios que compõem esse imaginário, advindos de diferentes espaços discursivos, tecem uma mescla na qual se observam lugares de encontro e de desencontro de saberes. Um deles, o espaço da mídia, é fortemente presente nessa composição. Em seus apelos, geralmente didatizados, saber a língua corresponde à capacidade de acessar um código "homogêneo e que passa por processo de degradação, de corrupção", segundo Baronas (2008). O autor afirma ainda que "atualmente, todos os nossos sentimentos e práticas são calculados, espetacularizados e positivados por uma espécie de humanismo político midiático de boas intenções. Na verdade trata-se de um movimento midiático ocidental que se constitui numa espécie de cruzada iluminista apta a esclarecer sobre o bom uso da língua, pedofilia, machismo, drogas, homossexualismo, violência doméstica, idosos, ecologia, armas, preconceito racial, produzindo e comercializando um imaginário de cidadania" (op.cit.). Esse saber amarra seus fios na instância do regramento, a qual institui a língua como perfeita, embora inatingível, e cujo "domínio" possibilitaria aos sujeitos ascensão social, estatuto de cidadania e certificação de pertença. Com relação às interpelações da ciência linguística, conduzem elas, em alguns de seus recortes, a levar-se em conta a possibilidade da diferença. Porém, esse levar em conta não se dá sem contradições. A começar pelo estatuto da relação língua-sociedade, tão ambígua e equivocadamente posto em diferentes áreas dos estudos da linguagem.

Considerar a língua como instância possível da diferença implica, sobretudo, abalar a noção de totalidade, admitir o fato de que nela há espaço para o possível e o impossível. Este último, emergente pela via do equívoco, onde encontra abrigo a variação, compreendida como diferença, como interdito ou mesmo como vacilo. A noção pecheutiana de vacilo é trazida 
neste contexto, por reportar ao fato de que os sujeitos não se inscrevem em um modo de dizer/pensar a língua que é homogêneo. O dissenso em torno do que seja a língua aceitável, os limites social e politicamente traçados nas fronteiras do "como se pode dizer x como não se pode" é o espaço de movência dos sujeitos acadêmicos, em direção a diferentes interpelações. A vacilação discursiva "afeta dentro de uma FD as sequências situadas em suas fronteiras, até o ponto em que se torna impossível determinar por qual FD elas são engendradas." (PÊCHEUX, 1983, p.314).

Nas palavras de Orlandi (2003, p.22), "a posição do sujeito é a configuração de um sítio de significância, um lugar de interpretação". No caso, trato de discursos de sujeitos com diferentes histórias de vida, diferentes experiências com o processo de aprendizagem da língua e que estão se constituindo como estudiosos a partir do contato com múltiplas correntes do pensamento linguístico contemporâneo. São as concepções às quais se identificarem acerca da língua que determinarão as posturas acerca dos fatos de língua e sua relação com os usuários. O trabalho com textualidades próprias da academia é, pois, espaço de excelência para pôr em causa as discursividades que irrompem nos gestos de escrita e de leitura, no sentido de os acadêmicos entenderem as produções linguageiras como trabalho humano, produto histórico social, de acordo com o que já afirmava Orlandi (1996). Segundo essa mesma autora, "conhecer uma língua não é apenas conhecer as formas engendradas pela gramática, mas também o valor social atribuído a elas". Reconstituir os trajetos que vão do senso comum à ordem da ciência, demarcando seus (des)encontros e embates e fazendo a língua trabalhar na história constitui, pois, possibilidade de desestabilizar evidências, estejam elas em uma ou outra ordem.

\section{A (RE)CONSTRUÇÃO DO TRAJETO}

Recorto, aqui, quatro sequências discursivas (SD), presentes na produção escrita realizada em sala de aula, a partir do chamado à reflexão acerca dos usos cotidianos da língua. As referidas SDs estão agrupadas em dois blocos, divididos de acordo com o modo de representação da variação linguística. A análise procurará mapear, via funcionamento da linguagem, os deslizes presentes nas duas posições, a partir dos quais se pode perceber o vacilo dos sujeitos.

Bloco I

SD1 - A língua demonstra-se, cotidianamente, capaz de inúmeras variações, essa 'inconstância' é positiva, não só porque a variação contribui para o enriquecimento da língua, mas porque permite que a língua, enquanto entidade viva e em constante transformação, aproxime-se da subjetividade.

SD2 - As variações são importantes, pois ao contrário do que se pode imaginar, facilitam a comunicação. No fim das contas, a gente abre a boca é pra ser entendido.

A posição-sujeito presente nas SD1 e SD2 filia-se ao lugar de saber que concebe positivamente a variação linguística. A construção da identificação materializa-se pela convocação, na SD1, do discurso-outro, refutando, via aspeamento do substantivo inconstância, o ideal de homogeneidade da língua. Da mesma forma, na SD2 o discurso-outro intervém via intercalação do segmento ao contrário do que se pode imaginar, em referência ao modo como é concebida a variação linguística no senso comum. Num gesto que transcende a simples substituição, no primeiro caso, e a simples remissão, no segundo, estabelece-se, de um lado, um ponto de distanciamento entre o que se acredita na ordem do senso comum, na qual a variação equivaleria à não estabilidade do status quo linguístico; e, de outro, a aproximação de uma ordem outra, a da ciência, na qual as diferenças passam a ser vistas 
como regularidades, porque constitutivas. A SD2 inscreve-se nesse mesmo domínio de saber, ao possibilitar o entendimento de que a diferença pode ser condição para a compreensão. Para além disso, materializa, via formulação, no fio do discurso, um espaço de variação na expressão "a gente", , substitutiva do canônico pronome "nós".

A tensão latente entre o saber que emana do senso comum, de que a língua é instrumento de comunicação, transparente, portanto, e, de outro lado, a inscrição na posição de que "entender-se" pode comportar a diferença, constitui instância de vacilação discursiva, no sentido de que ela "afeta dentro de uma FD as sequências situadas em suas fronteiras, até o ponto em que se torna impossível determinar por qual FD elas são engendradas" (PÊCHEUX, 1983, p.314), principalmente porque dá visibilidade a um ponto de tensão, estabelecido na ordem do dizer e também da interpretação.

A posição positiva acerca da variação linguística não se tece sem deslizes nessas duas sequências. Há que se considerar a representação que nelas se faz acerca da língua como entidade autônoma, vista em sua organicidade, relativizando-se a dimensão social. As variações podem ser entendidas, nessa perspectiva, como resultado natural do processo de evolução da língua. E os sujeitos usuários dimensionados na perspectiva de uma relação de subjetividade não necessariamente produzida por determinações históricas. Sujeitos e língua, assim suspensos, ausentes de condições de produção específicas, podem ser lidos como estando a serviço da comunicação facilitada, isenta de falhas, de diferenças, de tomadas de posição. A formulação afinal de contas, a gente abre a boca é pra ser entendido, constitui, por um lado, instância de resistência em relação ao imaginário de língua como transparente, a mesma para todos. No entanto, oblitera o fato de que as diferenças de registro, embora passíveis de compreensão, esbarram no não ser ouvido/atendido, considerando-se que em algumas instâncias, não saber utilizar a variante culta pode corresponder a não ter acesso à condição de cidadão.

\section{Bloco II}

SD3 - Com o desenvolvimento das sociedades ela (a língua) tornou-se complexa, tornando necessário criarem-se normas para o seu uso, visando a uma uniformidade que facilitaria o entendimento pelos usuários de uma certa língua.

SD4 - A língua, acima de qualquer coisa, é um instrumento de comunicação, seja em sua forma escrita ou falada. Mas, além disto, ela pode ser considerada, ainda que equivocadamente, uma distintora entre classes sociais, não é raro ouvirmos pessoas dizerem que aqueles que dizem 'pobrema' são ignorantes.

Nas SD3 e SD4 encontra-se posta uma posição de certo modo divergente daquela representada pelas SD1 e SD2, na medida em que há a explicitação da necessidade e relevância da normatização e da uniformização linguística. Na SD3 está, inclusive, referida uma relação de causa e efeito entre o desenvolvimento das sociedades e a complexificação da língua. O entendimento facilitado reaparece, porém, diferentemente do modo como está posto na SD2, ao produzir sentidos acerca de uma língua transparente, a mesma para todos, independentemente das diferenças, tangenciando o espaço dos sujeitos e dos modos como se inscrevem na ordem do social via linguagem.

O saber que propõe a língua como instrumento de comunicação emerge como repetível no fio do discurso na SD4, aí explicitado e formulado como função primeira da língua, em suas diferentes formas de realização. A questão da variação, dos diferentes

\footnotetext{
2 Esta expressão encontra-se em processo de gramaticalização no português brasileiro, sendo registrada na Gramática de usos do português, de Maria Helena Moura Neves (2000), Ed. UNESP, por exemplo. Contudo, na grande maioria das gramáticas que a abordam, especialmente as de uso escolar, consta em espaços marginais, como sendo registro próprio dos usos coloquiais da língua.
} 
registros, aparece sintaticamente "colada" à primeira, numa junção contrastiva, estabelecida via emprego dos relatores mas além disso / ela também pode... Essa junção opositiva pode gerar a leitura da variação como uma realidade que desestabiliza o ideal de comunicação. Esta leitura, possível, é logo em seguida atenuada pelo emprego do advérbio avaliativo equivocadamente, na medida em que formula a ideia da língua como distintora de classes sociais enquanto um julgamento inadequado. No entanto, acaba por produzir o efeito contrário, desde que a língua, reconhecidamente, comporta uma dimensão simbólica que submete seus usuários a diferentes juízos de valor. Ou seja, o equívoco encontra-se no substrato da formulação, não na perspectiva do engano, mas na possibilidade de o sentido ser outro.

\section{ALGUMAS AMARRAS (OU "SOLTURAS")}

As posições e saberes discutidos inscrevem-se, de modo conflituoso, na ordem do senso comum e na ordem da ciência. Na primeira, por ficar a língua reduzida a instrumento de comunicação $^{3}$, e da qual se espera grau máximo de transparência, a fim de que se realizem os propósitos comunicativos. Para tanto, assume relevância um projeto de homogeneização linguística, do interior do qual se apaguem as diferenças, os conflitos. Diferença que silencia, principalmente, o que marca os espaços de resistência dos sujeitos usuários de registros que não teriam "se complexificado" junto com as sociedades, ou seja, registros "não-padrão". Silencia-se, com isto, que a complexificação da linguagem, ao contrário do que se pensa, pode corresponder, em alguns casos, a desestabilizações da norma instituída. Valendo-me dos termos de Chauí (op. cit.), diria que se trata, na ordem do senso comum, da valorização do que é diferente, "maravilhoso", ou seja, da língua idealizada, intangível, em detrimento das regularidades cotidianas como passíveis de reconhecimento e reflexão. O que deveria funcionar como marcação identitária acaba produzindo o apagamento das diferenças próprias dos sujeitos, tais como pertença social, econômica, geográfica, étnica, entre outras; e o que delas decorre em termos sociais, econômicos e políticos.

Com relação à ordem da ciência (a linguística, no caso), vale lembrar que a concepção da diferença como passível de análise e sistematização, emergente em correntes teóricas da década de 50, ganhou corpo nos programas de ensino de língua portuguesa, no Brasil, na década de 70. O que se discutiu e se colocou no âmbito dos debates teórico-metodológicos, de lá para cá, no entanto, parece não ter sido suficiente, ainda, para romper com um paradigma centrado numa visão da linguagem como entidade transparente, ausente de conflitos. O modo como tais ocorrências são tematizadas nos enunciados em análise bem o demonstram esse lugar ainda predominantemente marcado pela assepsia.

Sylvain Auroux (1998) fornece-nos subsídios interessantes e densos para reposicionarmos a perspectiva da língua como instrumento de comunicação, essa uma tônica nas sequências selecionadas neste estudo. $\mathrm{O}$ referido autor produz um deslocamento significativo a partir da noção de hiperlíngua, cujo modelo é explicitado a partir dos seguintes requisitos:

- diferentes indivíduos têm entre si relações de comunicação;

- estas relações se efetuam sobre a base de competências linguísticas; competência deve ser tomada no sentido mais trivial do termo: trata-se das aptidões atestadas por sua realização;

- as competências lingüísticas individuais não são as mesmas;

- os indivíduos têm atividades sociais (...) (AUROUX, 1998, p.19).

\footnotetext{
3 O postulado da língua como instrumento de comunicação pertence a domínios de saberes da ordem da ciência lingüística também, no entanto, cristalizou-se no senso comum (em boa parte pelo papel de reprodução das mídias) como efeito de evidência.
} 
A língua em si não existe, continua o autor. Existem sujeitos que produzem a história (e são por ela produzidos) a partir da hiperlíngua, entendida esta como espaço/tempo estruturado pelos elementos anteriormente enumerados. Quer dizer, as instâncias comunicativas são constitutivamente atravessadas pelo seu tempo, pela sua historicidade, pelos sujeitos nelas insertos. Desse modo, trata-se, acima de tudo, de reposicionar esse laço, desfazendo a concepção da língua como um a priori na instância das trocas verbais.

Um lugar interessante para se observar como é discursivizada a questão da variação linguística e os modos como esta ressoar no espaço escolar/acadêmico é o dos instrumentos reguladores, tais como os PCNs, por exemplo. Percebe-se, neles, um movimento peculiar em relação à diversidade: ela é reconhecida como existente, contudo, o estatuto que se pensa lhe deva ser conferido no espaço escolar é contraditório. O postulado da não discriminação, do respeito às diferenças linguísticas é uma tônica em várias partes do texto dos PCNs, contudo, mantêm-se lacunar os sentidos políticos do tratamento discriminatório. Retomando afirmação que trouxemos de Guimarães e Orlandi (2006), no início deste estudo, pode-se dizer que não há uma colocação do "político como elemento próprio das relações sociais".

Observe-se o que consta nos referidos instrumentos acerca dos objetivos do ensino de Língua Portuguesa no Ensino Médio no que tange à variação linguística:

Frente aos fenômenos da variação, não basta somente uma mudança de atitudes; a escola precisa cuidar para que não se reproduza em seu espaço a discriminação lingüística. (...) A discriminação de algumas variedades linguísticas, tratadas de modo preconceituoso e anticientífico, expressa os próprios conflitos existentes no interior da sociedade.

(...)

A capacidade de uso da língua oral que as crianças possuem ao ingressar na escola foi adquirida no espaço privado: contextos comunicativos informais, coloquiais, familiares. Ainda que, de certa forma, boa parte dessas situações também tenha lugar no espaço escolar, não se trata de reproduzi-las para ensinar aos alunos o que já sabem. Considerar objeto de ensino escolar a língua que elas já falam requer, portanto, a explicitação do que se deve ensinar e de como fazê-lo (PCNs 2000).

$\mathrm{O}$ que parece se anunciar como o ponto de ruptura, na promessa de explicitação do que deva ser o trabalho da língua já conhecida, desemboca, na sequência do texto, em tomadas que focam a língua predominantemente como expressão oral, em situações de locução. Incide nisso o pressuposto de que à escola cabe ensinar um registro "não conhecido". Que língua estranha é essa? Abre-se, aqui, uma porta para o debate acerca do que seja a norma culta. Não é o propósito central deste estudo, mas cabe reportar, ainda que de passagem, à reflexão de Carlos Alberto Faraco, na medida em que este autor põe em causa a relação não-dicotômica entre as diferentes variantes de uma língua. Para tanto, ele parte do conceito de norma, elaborado pelo linguista Eugenio Coseriu", no início da década de 50, enquanto "conjunto de fenômenos linguísticos (fonológicos, morfológicos, sintáticos e lexicais) que são recorrentes, costumeiros, habituais numa dada comunidade de fala." (FARACO, 2008, p.37). Apresentase, aqui, deslocamento significativo em relação aos sentidos imaginariamente construídos acerca da noção de norma. Em se tratando dos usos normais, não são eles estranhos, o que nos conduz a inferir que a norma culta, assumida como objeto de ensino legítimo e primeiro seja, talvez, uma língua de fato estranha aos sujeitos, mais precisamente, aquela engessada nos manuais enquanto abstração da ordem do irrealizável. A mesma sobre a qual se prega o "domínio". E disso a questão que se impõe: Como dominar o inapreensível?

No âmbito dessa discussão Faraco (op.cit) aponta, ainda, a dicotomia imaginária estabelecida entre a dita norma e suas variantes, fronteira essa que, segundo o autor, pode ser explicitada a partir

(da) suposição tácita de que, por trás de toda variação constitutiva de uma língua, existe uma unidade sistêmica (que) adquiriu uma forma teórica na concepção de língua como um sistema social uniforme que 
se materializaria nos usos individuais (estes sim heterogêneos), resumida na famosa dicotomia langue/parole formulada por Ferdinand de Saussure (FARACO, 2008, p. 36).

Ora, estabelecer a norma culta como aquela a ser aprendida, é estabelecer os registros outros em oposição a um suposto centro de convergência, e nisso consiste o apagamento das implicações políticas dessas fronteiras que se estabelecem imaginariamente, a partir das quais se distribui de modos diferenciados o saber linguístico.

Retornando ao foco de nossa reflexão, pode-se pensar que os sujeitos que frequentam a academia, na qual buscam a formação em Letras, constituem o conhecimento sobre a linguagem em um espaço intervalar, no qual os saberes advindos da ordem do senso comum e da ciência ora se sobrepõem, ora dialogam, nunca sem conflitos. Vale dizer que, em ambas as instâncias, não há homogeneidades, além de uma confluência no processo de sedimentação dos saberes em cada uma delas. Nesse movimento, os sujeitos se marcam, a partir de suas inscrições, produzindo, também eles, lugares de "verdade" acerca da relação sujeitolinguagem. Esses lugares determinarão, em sua futura prática profissional, posições e consequentes práticas acerca do trabalho com a língua(gem) na condição de professores. E disso, a importância de, na academia, constituir-se um espaço de reflexão acerca das implicações políticas inerentes ao trabalho que se faz com o que designamos "aula de português". Reflexão também acerca do fato de que o sujeito não possui uma língua, as apropriações que faz dela são sempre imaginárias e inscritas na ordem da incompletude, principalmente porque ela não existe independentemente dos sujeitos e da história.

\section{BIBLIOGRAFIA}

AUROUX, Sylvain. Língua e hiperlíngua. In: Línguas e instrumentos linguísticos. Campinas, SP: Pontes, n.1, jan/jun de 1998. p. 17-30.

BARONAS, Roberto L. Breve ensaio sobre mídia e suavização de práticas linguísticas. In: Revista Anpoll, V. 1, n. 25, 2008. Disponível em http://www.anpoll.org.br/revista/index.php/rev/article/view/60. Acessado em 14 de agosto de 2009.

BRASIL. Ministério da Educação. Parâmetros Curriculares Nacionais - Ensino Médio: linguagens, códigos e suas tecnologias, 2000. Disponível em http://portal.mec.gov.br/seb/arquivos/pdf/livro02.pdf. Arquivo acessado em 25 de maio de 2010.

CHAUÍ, Marilena. Convite à filosofia. São Paulo: Ática, 2004.

FARACO, Carlos Alberto. Norma culta brasileira: desatando alguns nós. São Paulo: Parábola, 2008.

GADET, Françoise. "1977: Sur um moment-clé de l'emergence de la sociolinguistique em France. In: Cahiers de quelques de I'ILSL, n. 20, Paris, 2005, 127-138.

GUIMARÃES, Eduardo e ORLANDI, Eni. O conhecimento sobre a linguagem. In: PFEIFFER, C.C e NUNES, Horta (org). Introdução às ciências da linguagem: linguagem, história e conhecimento. Campinas-São Paulo: Pontes Editores, 2006, v.2, p. 141-157.

MOURA NEVES, Maria Helena. Que gramática estudar na escola? São Paulo: Contexto, 2004.

ORLANDI, Eni. Terra à vista. São Paulo: Cortez, 1990.

A leitura proposta e os leitores possíveis. In: ORLANDI, Eni P. (org). In: A leitura e os leitores. Campinas, SP: Pontes, 2003. 
ORLANDI, Eni P. A linguagem e seu funcionamento; as formas do discurso. São Paulo, Brasiliense, 1983.

PÊCHEUX, Michel. A análise de discurso: três épocas(1983). In: GADET, F. \& Hak, T. (Orgs.). Por uma análise automática do discurso: uma introdução à obra de Michel Pêcheux. Campinas, SP: Unicamp, 1990. 